Forthcoming in Regulation \& Governance

TITLE: Understanding "corruption" in regulatory agencies: The case of food inspection in Saudi Arabia

Saad Al-Mutairi*, Ian Connerton** and Robert Dingwall***

* Public Department of Environmental Health, Municipality of Riyadh, Saudi Arabia

** School of Biosciences, University of Nottingham, Loughborough, LE12 5RD, United Kingdom

***Dingwall Enterprises Ltd/Nottingham Trent University

RUNNING HEAD Corruption in regulatory agencies

CORRESPONDING AUTHOR Robert Dingwall, Dingwall Enterprises Ltd, 109 Bramcote Lane, Wollaton, Nottingham NG8 2NJ Robert.dingwall@ntlworld.com +441159281973

\title{
Acknowledgments
}

Saad Al-Mutairi is grateful to the Saudi government (Municipality of Riyadh) for funding the PhD scholarship which supported this study. Neither Ian Connerton nor Robert Dingwall received any specific financial benefit for their contribution beyond their role as supervisors. Many thanks go to the participating Saudi Food Inspectors, without whose goodwill this study would not have been possible. Previous versions of this paper were presented at the annual meetings of the Socio-Legal Studies Association, Bristol, April 2018 and the Law and Society Association, Toronto, June 2018. We are grateful for the comments and suggestions received on those occasions, particularly from Nancy Reichman. 


\begin{abstract}
Corruption is a relatively neglected topic in studies of regulatory agencies. The label is applied to a wide range of deviations from behavioural standards derived ultimately from Weber's account of the ideals of Prussian bureaucracy. This paper draws on a study of the work of Saudi Food Inspectors (SFIs) to argue that it is unhelpful to reduce a complex phenomenon to simple allegations of malpractice that can be managed by disciplinary sanctions. Our data show that irregular behaviour by street-level agents may be deeply embedded in the expectations that members of a society have of one another. It is less a matter of personal gain than of maintaining one's recognition as a fellow-citizen. Such behaviour is not easily changed through sanctions directed at individual inspectors. Our study does not exclude the possibility that irregular behaviour can be motivated by personal gain, and properly managed by criminal or similar penalties. However, it does propose that research should be more sensitive to the contexts within which irregular behaviour occurs rather than treating 'corruption' as a uniform and homogenous phenomenon.
\end{abstract}

Keywords: Corruption; Discretion; Food inspector; Saudi Arabia; Regulation 
Although there is a substantial literature on the topic of corruption in government and public agencies within economics, development studies and political science, this is a relatively neglected issue within regulation studies. It is, however, a complex and multi-facetted phenomenon that raises important questions for the design and practice of regulatory agencies. In particular, the study of "corruption" brings novel insights into core topics like the role of discretion in regulatory enforcement and the interface between agencies and their societal environments. It takes us into what Vaughan (1999) has called the 'dark side' of these organizations, which may lead to a greater understanding of their everyday practice. The paper begins with a brief and selective overview of relevant literature before introducing a case study, the work of food inspectors in Saudi Arabia. This is documented through a combination of participant observation, interviews, community talk, official websites, and local media reports. These data show that much of what is labelled as 'corruption' has less to do with personal economic gain than with recognition as a fellow citizen. We conclude with a discussion of the limitations of reform agendas that focus purely on increasing disciplinary pressures on street-level workers.

\section{What do we mean by "corruption"?}

The substantial reviews by Bardhan (1997), Jain (2002), and Kurer (2005), of literature in economics, politics and development studies, are a useful starting point and do not seem to require replication for the purposes of this paper. They note that the term "corruption" has a variety of applications. In a political context, it may refer to gains primarily in terms of the use of political power for sectional interest, which Jain describes as 'grand corruption'. In a legislative context, it may refer to the extent to which law-makers are influenced by the 
activities of lobbying groups through bribery or campaign donations, which Jain describes as 'legislative corruption'. In an economic context, it is most commonly used to refer to the use of a public office for private gain, which Jain terms 'bureaucratic corruption'. These broadly correspond to Heidenheimer's (1970) definitions of public interest, public opinion and public office corruption. Kurer suggests that, whatever labels we use, they all rest on a more fundamental assumption - that a state ought to treat equally those who deserve equally, which he calls the 'impartiality principle'. This is essentially a restatement of Weber's (1964, pp.329-41) classic argument about the rise of bureaucracy as an organizational expression of the modern state. The bureaucrat is the impersonal administrator of a body of rules that apply equally to all those within their sphere of application. Weber's description is an ideal type. Subsequent scholarship has emphasized that rules necessarily rest on interpretation by lowlevel enforcers (Lipsky 1980), although the ideal may still be an important constraint on the scope for interpretation (Davis 1979). 'Corruption' may also be used to describe some private sector behaviour: Bardhan gives the example of using bribes or connections to obtain a scarce good like a ticket for a sell-out concert, theatre performance or sports event, rather than the promoters setting a market-clearing price.

The ideal of impartiality is associated with notions of legality - but not all corruption is clearly illegal. It is not an offence to tip the maitre d' to get a better table in the restaurant or to promise a lucrative private sector job to a retiring public official. Moreover, while corruption may have a negative impact on economic relations, it may also enhance efficiency in otherwise inefficient economies - it greases wheels that would otherwise remain stuck. Bardhan (1997, p. 1322) quotes Samuel P Huntington: 'In terms of economic growth, the only thing worse than a society with a rigid, over-centralized, dishonest bureaucracy is one with a rigid, over-centralized, honest bureaucracy.' Paying a price to circumvent a 
bureaucratic obstacle may increase net welfare by favouring those able to get the greatest returns from the investment. As Bardhan points out, this position makes a number of empirically difficult assumptions about the information available to the parties, but these are not necessarily fatal to the argument in practice. Jain also observes that corruption may reduce the costs of government by allowing for lower salaries to be paid to public employees. In a sense then, bribes might be thought of as a form of selective taxation or co-payment by those seeking to use public services (Ang 2016). Most analysts, however, tend to highlight the negative aspects of corruption in terms of allocative efficiency and transaction costs.

There have been numerous attempts to develop explanations of corruption. All these reviews are critical of norm-based explanations, which account for corruption in terms of the values and practices of different national or local cultures. As Bardhan, in particular, observes, such explanations can easily end in tautology - there is more corruption in a country because its norms are favourable to corruption... We might also add that it is a rather static view of culture and norms, which does not reflect the dynamics and diversity of their enactment in real societies. Economic models of corruption focus more on interests than values and the extent to which institutions and markets create structural opportunities and incentives for corrupt behaviour. This is reflected in the policy options (Gillespie \& Okruhlik 1991). Moral exhortations are of limited value compared with structural reforms, whether legal or organizational. Nevertheless, proposals for the greater moralization of public officials are not uncommon (Nolan García \& Aspinwall 2017). Opportunities for corruption may be removed by deregulation - so there are no relevant rules that can be invoked to facilitate or obstruct the provision of a service. Alternative routes to service provision may be developed so that particular officials lose their monopoly over granting or withholding access. Disciplinary measures may be strengthened, with greater sanctions applied to corrupt public officials, up 
to and including the death penalty in some countries (Gillespie \& Okruhlik 1988). It is notable that most efforts at reducing corruption have focussed on the behaviour of public officials, including judges, politicians and legislators, and the organizations in which they work, rather than on the behaviour of citizens. The focus is on the supply of corrupt behaviour, not the demand, although Gillespie and Okruhlik (1991, p. 80) do make a passing reference to the possible role of public education and community vigilance as sources of pressure for impartial conduct.

Much of the literature operates at a fairly high level of policy or abstraction, dealing with grand or legislative corruption or using economic theory to model bureaucratic behaviour. We have found relatively few references to petty corruption in studies of the everyday work of public officials. This may be because most such research has been carried out in countries where corruption levels are relatively low. However, it may also reflect a discriminatory framing of the problem itself. The literature from North America, Europe and other developed countries has been very concerned with the use of discretion (Hawkins 1992; Silbey 2011; Piore 2011; Morgan 2015). If laws, regulations and other types of rules are not self-interpreting in their application to specific situations, then street-level bureaucrats must necessarily work to match individual cases to the texts in ways that will be accepted as legitimate by key stakeholders. In the course of this process, it is not uncommon for a variety of social, economic, cultural and attitudinal factors to shape the outcomes in ways that have unequal effects. Where does the justified use of discretion end and corruption begin? Is it solely a matter of the direct offer of a bribe or an implied exchange of favours? There are many circumstances in which it is entirely accepted that I will back your project in an organizational meeting with the expectation that I can, at some future time, call on you to reciprocate. Is 'corruption' just another way to 'other' the Global South? 
This study uses a case study of food inspectors in Riyadh, Saudi Arabia, to investigate the everyday engagement between street level public officials and owners, managers and workers in the industries that they regulate. Their practice is widely acknowledged to deviate from the impartiality principle, and is the object of various reform efforts. Our study, though, is less immediately interested in the issues of reform than in understanding how the inspectors' work comes to take a particular form and why this has come to be regarded as problematic.

\section{The Saudi Context}

The Kingdom of Saudi Arabia was established in 1932 under King Abdulaziz Al Saud, following a series of territorial wars and other conflicts as the Ottoman Empire declined and lost its grip on the Arabian Peninsula. Vast reserves of oil were discovered in 1938 and the country rapidly became one of the wealthiest per capita in the world. The total population is currently about 33 million, of whom about 60 per cent are Saudi citizens (General Authority for Statistics, Kingdom of Saudi Arabia 2018). There are also believed to be a large number of undocumented workers, who are frequently encountered in the food industry. The population has grown rapidly: estimates suggest that the population was around 2.5 million in the early 1930s ('SAUDI ARABIA : Population Growth of the Whole Country’2003).

Saudi society was originally based on nomadic tribal groups or clans and unaffiliated groups of freeborn tradesmen, artisans, merchants, and scholars. Tribal membership was the traditional source of social and economic status, often cemented by endogamous marriage alliances. Despite urbanization and population growth, tribes continue to have a significant influence on social, cultural and economic relationships, although their political engagement is regulated and tightly constrained by the Ministry of the Interior. The process of 
urbanization, and the creation of a centralized state, has, however, also greatly enlarged the pool of citizens who do not have a strong identification with any tribe, beyond their family name. Nevertheless, tribal affiliation is an inescapable element of the context for leadership and management in every Saudi public agency. These agencies also tend to be characterised by common organizational features, such as a reliance on central authorisation rather than local initiative, poor coordination with agencies in related fields, and confused and overlapping distribution of organisational duties and functions among their staff (Al-Awaji 1989; Al-Yahya 2009).

Successive rulers have tried to modernize aspects of the society, without losing its distinctive character as an Islamic state. Although these efforts began in the 1970s under King Khalid bin Abdulaziz Al-Saud (1975-82), they have acquired much greater impetus in recent years through the Vision 2030 ('Saudi Vision 2030' 2016) programme launched in 2016 by the Crown Prince Mohammad bin Salman Al-Saud . This is intended to develop a more diverse economy that will be capable of employing a higher proportion of Saudi nationals, reflecting the growing problem of unemployment among the under-30s. It includes specific commitments on improving governance, administrative efficiency and the rule of law, with an explicit statement on transparency:

We shall have zero tolerance for all levels of corruption, whether administrative or financial. We will adopt leading international standards and administrative practices, helping us reach the highest levels of transparency and governance in all sectors. We will set and uphold high standards of accountability (http://vision2030.gov.sa/en/node/106). 
The Crown Prince has been particularly associated with a drive to reform the economic behaviour of the country's elite, with the arrest and detention of many princes and ministers in 2017 and the dismissal of others from influential positions (New York Times 2017). The target was 'grand corruption' rather than 'bureaucratic corruption', which is the focus of this paper, but these actions sent a powerful signal about the commitment to change.

This research project was carried out before the publication of Vision 2030. However, a National Anti-Corruption Commission (NAZAHA) had previously been established based on the Royal Order $N^{o .}(\mathrm{A} / 65)$ on 18 March 2011. According to its Mission Statement, the commission aims to maintain integrity, promote transparency, and combat financial and administrative corruption in all forms, manifestations and means (Nazaha 2012) . It has wide-ranging powers to investigate and report on citizen complaints, to promote good practice in state agencies, to commission research, and to develop educational materials for government employees and the general public. Disciplinary actions remain the responsibility of individual agencies. There has been a steady but modest improvement in the international rating of Saudi Arabia by such measures as the Corruption Perceptions Index (Transparency International 2018).

The modernization process has also had an impact on food safety regulation. This is an area of great significance for Saudi society. The country is almost entirely dependent on imported food and its climatic conditions - the high summer temperatures in some areas of Saudi Arabia - present serious challenges for food transportation, distribution and storage. Food processing industries employ large numbers of migrant workers, often undocumented. Adulteration and food-borne illnesses are recognized as issues of serious concern for the 
regulators. About two thirds of the reported cases of food poisoning originate in the commercial sector subject to inspection (Al-Mutairi 2013). The Saudi system of food safety regulation has been undergoing both legal and organizational reform since the establishment of the Saudi Food and Drug Authority in 2003, with the gradual transfer of functions from other ministries and state agencies to this more powerful central body (Al-Mutairi et al 2015). There has been a programme to upgrade the qualifications of food inspectors, who may have little more education than a high school certificate, and to motivate their enforcement efforts through the payment of bonuses for successful prosecutions. While the educational level of new recruits has been rising, there remain serious problems in motivating inspectors to act as the kind of rational, impartial bureaucrats depicted in studies such as those of Hutter (1988) and Hyde (2015) from the UK.

\section{Data and Method}

The study is based on participant observation of 200 visits carried out between March and June 2011 by 25 Saudi food inspectors, selected from 653 working in Riyadh city at the time. The inspectors were drawn from nine divisions in different geographic locations. All the participants were male: there are very few women inspectors and it would not have been possible to anonymize any who participated. The researcher (S A-M) accompanied participants during their routine daily work, visiting premises involved in food preparation and related services, and documented their interactions and interventions with the people working at these sites. Each inspector was observed for three working days, because their pattern of work varies from day to day, for approximately six hours. In between visits, the researcher carried out informal interviews with the inspectors about their knowledge and 
understanding of various aspects of law enforcement and food hygiene practice, and the ways in which they applied this knowledge. These conversations covered the following topics:

- How inspectors see themselves and other people

- How they view the situations they encounter

- What they do and say in various circumstances

- $\quad$ How they organise themselves and their daily work

- What occurred before, during and after the observed events

- How typical are these are of routine work, according to the inspectors' accounts

- What are really important breaches of regulations and what can be overlooked or dealt with by informal means

- How inspectors deal with information they obtain (the flow of information) and how do they handle documents generated during their work (i.e. review and reading relevant records and reports)

Data were recorded by hand in a notebook in the form of Arabic field notes and later transcribed into English. Participants were not comfortable with the idea of audio recording and this was not pursued. Local media were also reviewed for relevant reports of actions by food inspectors.

Inspectors were generally interested and keen to participate in the study, considering that it would help to solve problems that they recognized but were unable to manage. S A-M had worked in the agency for about ten years at the time of the study and many participants knew 
and trusted him as a work colleague who would understand the issues that they faced in their everyday practice. Those inspectors who did not know him personally were reassured by the evidence of official approval for the study but the confidence of other colleagues was more critical. There was no evidence of reluctance to discuss personal or organizational issues, the difficulties they faced in practice or the negative view of the agency by many outsiders. The continuing validity of the data has been verified by reference to S A-M's subsequent and current experience as an employee of the agency.

The data were analysed using a grounded theory approach, which has been described at length elsewhere (Glaser and Strauss 1967; Strauss and Corbin 1997; Charmaz 2006). The main elements are summarized in Figure 1

\section{Figure 1 about here}

Data were coded under three major topics, derived from a review of literature on street level bureaucrats, police and other enforcement agents: professionalism, law enforcement; and peacekeeping (Al-Mutairi 2013). Within each of these, various themes were identified and coded for more detailed analysis. The present paper is based mainly on the data coded as relevant to the law enforcement topic and its themes: Overlooking the law; Breaching the law; Decisions made to increase productivity, rather social protection or enhancing the public image of the SFI; Direct and indirect corruption (hospitality); Political order (interventions of agency staff); Social order (interventions of relatives, friends, etc.). This selection of topic and themes bears directly on the questions about impartiality in the everyday practice of the food inspectors that are central to the notion of 'bureaucratic corruption'. 


\section{The Notoriety of Food Inspectors}

In the nature of participant observation, it is difficult to display direct evidence of corruption or partiality among food inspectors. For obvious reasons, such behaviour is unlikely to occur in the immediate presence of even a trusted observer. We can, however, also come at this issue indirectly from two sources. These are media reports of prosecutions and statements made by inspectors in their interactions with S A-M.

Media reports

On 25 May 2013, the MBC TV channel featured four Saudi food inspectors in Riyadh city, on programme $\mathrm{N}^{\mathrm{o}} \cdot 260$. The programme examined administrative, regulatory, and field issues in their agency. During the discussion, one inspector stated that they encountered many temptations and the offer of bribes from restaurant owners, but they lacked the evidence to prosecute them.

There are however, regular reports of food inspectors being prosecuted for misconduct. Table 1 summarizes a number of these cases.

\section{TABLE 1 about here}

It is so taken for granted that food inspectors can be corrupted that the refusal of a bribe is considered to be a newsworthy story: Two local newspapers, Okaz and A.Riyadh reported, on 13 and 18 July 2008 respectively, that a food inspector had refused a bribe offered by a food business worker in the northern region of Saudi Arabia to ignore hygienic offences, and that 
the inspector had been rewarded by his superiors. It is also common enough to attract impersonators seeking to take advantage of the reputation for corruption:

- Alyaum newspaper reported on 26 April 2009 (issue 13099) that the agency had received a complaint from a food business worker about a man claiming to be an inspector and asking for money in order to avoid a fine for breaches of the regulations on hygiene.

- Al-Eqtisadiah newspaper reported on 9 August 2008 (issue 5416) several cases of the impersonation of food inspectors discovered by Riyadh Municipality. This was associated with the introduction by the municipality of an official telephone line for businesses to confirm the identification of a food inspector (Municipality of Riyadh 2009).

The prosecutions focus on cash payments. However, a good deal of what is understood to be bureaucratic corruption takes less obvious forms. The interview data gave us a more subtle picture of the behaviour that might be involved.

\section{Interviews}

Interview data always needs to be treated with some caution because informants are both reporting events and presenting an account of themselves as reasonable, rational and moral actors in the context of those events (Dingwall 1997). However, when we are dealing with reports of corrupt behaviour, this is not necessarily a reason to reject the data. Clearly, S AM's informants are concerned to depict themselves as people who do not engage in this behaviour, even if others do so.

Some inspectors have a corrupt behaviour and this kind of behaviour definitely negatively influences the reputation of good inspectors inside society and food agency (SFI 3, Food Factories \& Sampling Division). 
Nevertheless, they clearly regarded it as a reasonable question for him to ask, especially in the light of the sort of media coverage cited above. They may not admit to corrupt actions themselves but they can easily relate stories about their colleagues and managers. These do not have the extreme character of 'atrocity stories' (Dingwall 1977) but are remarkably mundane. This is just how it is in everyday practice. In analysing these accounts, we have found three particular types of corruption: nepotism; inappropriate hospitality or gifts; and direct bribes. Our interest here is in the development of a taxonomy of corrupt behaviours and the ways in which they are embedded in the everyday practice of the agency rather than in measuring their relative incidence or prevalence. A different kind of study would be required for that. All we are claiming here is that these behaviours are considered by agency staff to be so common as to be unremarkable.

\section{$\underline{\text { Bribes }}$}

As might be expected from the media reports, inspectors could easily describe situations where they personally had been offered bribes:

Many years ago, a Sudanese food worker put money into my pocket during an inspection visit. He aimed by this behaviour to build a good friendship. I threw this money away and reprimanded him, but I did not have any evidence to condemn him (SFI 13, Municipality A).

One day, an owner of a business (Saudi old man) put money in my hand at the shop and said: this is the value of your dinner. Thereafter, I did not take any action because he was an old man and he was not aware of the risks of what he was doing. I did not know 
what sort of action or practical measures needed to deal with such situation (SFI 22, Municipality E).

One Indian food worker put money in the health inspection's record during an inspection visit. I reprimanded him and reported that to my supervisor who, unfortunately, did not take any action (SFI 15, Municipality B).

We do not attach any particular significance to the fact that many of the protagonists in these stories are foreign workers rather than native Saudis. Although they could mark a distinction between 'them' and 'us', it is also a matter of simple demography that workers tend to be foreign even if the business owners are Saudi. What is notable, though, is the distrust of supervisors and managers that is apparent in these accounts. Although there is a disciplinary framework in place, bribery is not represented as a matter that attracts much attention from the organization. The inspector at street level is left to manage it in accord with their own conscience and assessment of the risks of acceptance or refusal.

I admit the prevalence of this phenomenon in our society for several reasons. For example, there is an absence of inspector awareness of Islamic instructions that prevent this behaviour... inspectors who have this behaviour are not punished, and there is a strong relationship between some inspectors and offenders (especially workers) (SFI 13, Municipality A).

The reasons behind this phenomenon are: less income of some inspectors who lack Islamic instructions that prevent this bad behaviour, temporary jobs of inspectors. Let me tell you this story: An Indian food worker put money in my hand during an 
inspection visit at a grocery. I informed the police who did not take any action, because I had no evidence. Also, I did not tell my supervisors at the agency, because they did not react to a previous issue with another worker who offered to bribe me (SFI 20, Municipality D).

\section{$\underline{\text { Gifts and hospitality }}$}

Outright cash payments lie at one end of a continuum of exchanges intended to promote good relations between food inspectors and the businesses they are charged with regulating. We have direct evidence of this: in 8 per cent of the observed visits there was some kind of offer of free or discounted food or hospitality. For example, an event was observed between inspector SFI 17 (Municipality C) and the manager of a roasting shop, where an offence had been identified. After giving some food to this inspector, the manager said: 'Instead of the offence's value, I will give you the value of the ticket to pay it to your department.' The inspector was surprised and did not comment on this statement. However, other inspectors did pick up on the issue. For example, at a bakery, a food worker offered drinks to inspector SFI 14 (municipality A). The inspector responded with this question: 'Do you offer this service to the people on the street?' When the worker said that he did not, the inspector left the topic. At another restaurant, though, the same inspector was made a similar offer and lectured the worker there on the wrongfulness of their action and the importance of not repeating it.

Because the food inspectors cover a wide range of businesses, the services offered can be quite diverse. This is from an interview:

Many facilities are introduced by workers or owners of businesses to the inspectors. For example, at the laundry he can wash his clothes free; at the restaurant he can eat free of 
charge; and so on. Let me tell you this story: a worker noticed my car was open and he put food items in my car during the inspection. At the end of the inspection visit. I thus informed him that this action is wrong and against the law. Then he removed those items and returned them to the shop. (SFI 25, Follow-up \& investigation of food poisoning outbreaks).

A food inspector visited a roasting shop on 4/10/2017. During the visit, a food worker offered to eat lunch with him, He openly offered a bribe to him by giving the inspector money outside the shop. The inspector reported the issue to his manager ( $\mathrm{S}$ A-M) who investigated the issue in his office with the owner of the business and the worker leading to official acknowledgment of the action. Then, S A-M communicated with the leaders of Public Department of Environmental Health in order to complete the legal process with the General Directorate of InvestigationMinistry of Interior

It is not easy to determine the point at which practices of this kind shade from the sort of relationships that Hutter (1988) describes as persuading UK businesses towards regulatory compliance through the force of goodwill into incentives to overlook offences. Hutter, for example, mentions in passing the case of an inspector visiting a local hotel owned by a councillor to inspect the swimming pool: 'After coffee, he told me to go and check the pool...'(Hutter 1988, 172). Clearly, neither the inspector nor Hutter thought that there was anything wrong with him accepting the coffee from the business owner. Nevertheless, there is obviously a point at which taking up the offer of a drink may compromise the inspector's ability to take enforcement action. 


\section{$\underline{\text { Nepotism }}$}

We have already mentioned the apparent lack of confidence in the support from superiors for street-level enforcement actions. This is most directly linked to the family or kinship connections that may be invoked to reduce or cancel penalties that have been issued by the inspectors. These connections are part of the phenomenon of wasta, an Arabic word that may be translated as influence or clout, the ability to get things done by mobilizing personal networks rather than through officially recognized state or market relationships (Cunningham \& Sarayrah 1993; Hutchings \& Weir 2006; Tlaiss \& Kauser 2011). NAZAHA (2016) found in a recent study of three regions in Saudi Arabia regions that nepotism was one of the most common forms of corruption.

Some of the gift-giving and hospitality described above can be seen as an aspect of wasta, where business owners are targeting the inspectors in an attempt to enrol them in their own networks. For the inspectors, however, it is more obviously a subject of complaints about their enforcement actions being undermined by colleagues or agency superiors.

I am positive that the action taken against this business will be no action, or at least a written warning, because there is some sort of friendship between the owner of this business and my leaders (SFI 20, Municipality D).

Our supervisors order us to inspect the business, but at the same time some businesses are exempted from our visits, because we found that those businesses belong to our supervisors who turn out to be the owners of these businesses (SFI 15, Municipality B).

This was also directly observed in relation to three businesses visited during the fieldwork. In two cases, an inspector was checking whether the premises complied with the terms of their licences for food processing. S A-M and inspector SFI 23 (Municipality E) visited a restaurant 
that was due to renew its licence. There was clear evidence of poor hygiene and noncompliance with the regulations for food storage, equipment washing and food preparation. This amounted to a list of major offences and the inspector recommended to his supervisor that the licence should not be renewed and the business forced to close. However, S A-M observed later that the licence had been renewed as the result of intervention by another inspector. The second case with SFI 23 involved a fish shop, which also had defective premises. The owner claimed it was similar to other shops owned by his friends that had been approved for licencing. Another inspector in the municipality, who was related to the owner, tried to persuade SFI 23 to renew the licence, but, on this occasion, the inspector was able to resist. In a third case, inspector SFI 8 (Emergency Call Team) visited a grocery following repeated complaints about the sale of yogurt beyond its expiry date. The owner told SFI 8 that his cousin was also a food inspector. Although SFI 8 issued a ticket for a summary fine, this was later cancelled following the cousin's intervention with a supervisor.

The practice of wasta is deeply embedded within Saudi culture. Although it tends to be more evident in relation to close family and business associates, it is, in principle, an exchange relationship that can range much more widely: any of the thousands of people who share a family name can, for example, attempt to use this as evidence of shared clan membership that might require an individual to make a decision in their favour. As we noted earlier, such practices have both positive and negative elements. On the one hand, they can compensate for bureaucratic failures or mistakes and deliver discretionary solutions to citizen problems. On the other, many of these problems are themselves caused by wasta, the obligation to favour relatives or clients rather than merit in appointing to public sector jobs and to tolerate poor performance rather than asserting work discipline (Al-Awaji 1971; Al-Saud 2000; Rice 2004; Tlaiss \& Kauser 2011). Participation in wasta is also central to a person's identity as a Saudi. 
As Champion (2003, p. 99) notes, 'traditional values have come through into the modern state in Saudi Arabia: a man's first loyalty is to his family, then his tribe, then his country. Nepotism is a virtue and it would shame a man to refuse to help or give a job to a close relative'. Saudi public agencies are shaped by deep-rooted traditions that bind citizens together in a sense of solidarity and mutual obligation, even at the expense of contemporary values of efficiency, effectiveness and impartial administration.

We cannot draw a direct connection between corruption, inspection quality and food-borne illness. However, food quality and safety are recognized as important problems in Saudi Arabia and the systems of regulation, inspection and quality assurance have been the object of sustained state action since 2003.

\section{Dilemmas of Regulatory Reform in Saudi Arabia}

Food inspection in Saudi Arabia is a case study in the sort of low-level official behaviour that is replicated widely in other public agencies in that country, and, indeed, in many other Global South countries. It seems to correspond to Jain's (2002) category of 'bureaucratic corruption', which should be distinguished from 'grand corruption', even though this may rest on similar foundations, as in Wrong's (2009) account of tribalism and malfeasance in Kenya. While each country and agency has its own unique history and culture, certain features are common and exemplified by this case. The most important is the belief among 'modernizers' that the creation of a workforce of impartial public bureaucrats of the kind described by Max Weber is an essential condition for the efficient and effective workings of a market economy. Practices such as wasta and its equivalents, like guanxi in China, are seen as an obstruction to this process (Hutchings \& Weir 2006). They are to be eradicated by intensified work discipline, backed up by criminal sanctions, imposed from above. However, 
these practices have their own logic and rationale, which is not displaced by modernization, at least in its early stages. The food inspectors, and other public servants, are faced with a difficult choice between their identity as bureaucrats and their identity as Saudis.

Weber's (1964) classic analysis of the development of bureaucracy links this to the shift from traditional or patrimonial principles to rational-legal authority as the source of political legitimacy. Traditional authority rests on collective understandings of local hierarchies and mutual obligations. Patrimonial authority derives from inherited roles - kings, lords, clan chiefs, etc. Political structures rest on personal relationships and take the form of loose networks of patronage and preference, where the deference or obedience of subordinates is exchanged for the protection and goodwill of superiors. Ironically, as Felson (2011) notes, it is the shift from these principles that creates the possibility of corruption. Both traditional and patrimonial systems accept that nepotism, bribes and hospitality are intrinsic features of their operation. As such they are not to be judged as corrupt. It is only when the impersonal principles of rationality, expressed in law, are introduced that behaviours can be labelled as 'corrupt' within the terms of the system.

It must be remembered that Weber was working with ideal types, models derived from empirical observation rather than specific actual societies. In practice, traditional societies often had elements of rational-legal authority in the form of law and rational-legal societies retained elements of traditional authority in their ceremonial institutions and private spaces. Although Weber took the feudal societies of medieval Europe as his source of inspiration, we should, then, avoid using the language of feudalism to describe contemporary Saudi Arabia. It is, rather, a society whose pathway into the $21^{\text {st }}$ century has retained significant elements of 
patrimonial and traditional authority in the form of its monarchy and in the mutual commitments between tribal or clan members, identifiable by their family name. Clan solidarity is not just a matter of deference to the acknowledged head but a recognition of actual or fictive kinship that creates expectations and obligations between those who share this claim.

Since the discovery of oil, however, Saudi Arabia has also been forced to engage with other societies where rational-legal authority is more important. The trade in oil, and the associated requirements in material, economic and social infrastructures, imposes participation in an international legal order which comes to permeate most aspects of everyday life. Supply contracts must be written, transport and harbour projects require an array of licenced professionals, whose relationships must be specified and defined, and associated services in health, housing and leisure industries must be developed on a basis acceptable to different kinds of expatriate workers. These are powerful isomorphic pressures on the state as a whole (DiMaggio and Powell 1983). However, the development of public bureaucracies to implement this rational-legal order may occur more rapidly than changes in the principles of authority. Traditional and rational-legal orders can co-exist and compete. While this has been extensively studied in the field of legal pluralism (Griffiths 1986, Merry 1988, Snyder 1999, Forsyth 2007), the present instance is not clearly such a case. While Saudi Arabia retains parallel religious and state legal institutions, for example, the maintenance of clan solidarity does not have a set of recognized office-holders, associations or organizations concerned to define and enforce its conventions. Some might argue that the force of these conventions still makes them eligible for consideration by the sociology or anthropology of law, but we would not want to insist on this. Traditional authority here is much more a matter of identity and the mutual expectations that lead citizens to recognize one another as members of the same moral 
community. Barbalet (2018) reaches a similar conclusion about guanxi from a slightly different theoretical perspective where he sees it as a form of gift exchange essential to maintain one's social standing.

In the present case, the Saudi system of food regulation takes a classic bureaucratic form, with inspectors expected to implement laws and regulations handed down from above in a rigid and impartial fashion. There is, for example, a strong emphasis on fixed monetary penalties in response to all identifiable offences. The agency is also encouraging inspectors to wear a uniform as a regulatory sign (Hermer \& Hunt 1996), identifying them as officials rather than as individuals. While this may conform to the idea of an imagined bureaucracy, it does not, however, correspond to any real one. Weber acknowledged that his account depicted an ideal type rather than any specific agency. However, a century of further research has underlined the inescapable elements of discretion that form part of any bureaucracy's work. Laws and regulations are not self-interpreting but always need to be aligned with the facts of particular cases (Lipsky 1980; Travers \& Manzo 1997; Dingwall 2002). Moreover an orientation towards strict enforcement is, in practice, costly to an agency in terms of goodwill and resources. The agency's work is made more difficult (Bittner 1967; Hawkins 1983; Hutter 1988). Its legitimacy may be compromised if sanctions are used in a way that violates public notions of fairness and 'common sense'. Aggressive enforcement also increases the likelihood of conflict and confrontation with the people being regulated. This is not a trivial risk in Saudi Arabia: we identified five media reports of incidents where food inspectors had been beaten or stabbed between August 2008 and June 2010. 
It is, then, inevitable that street-level workers will always have some space to use discretion. Much like the UK inspectors described by Hutter (1988), the Saudi inspectors often worked through building relationships with regulated businesses and seeking to persuade them towards improved standards rather than penalizing them for every technical offence. This was part of what they saw as a more 'professional' approach, most obviously reflected in their resistance to wearing uniforms. Particularly among the more recent, and better-educated, recruits there was a desire to focus on the objective of safe food rather than on the details of process or premises. S A-M observed, for example, inspectors waiting outside food processing businesses using undocumented workers. They allowed themselves to be recognized and gave time for the workers to leave the premises rather than being obliged to notice non-compliance with rules about documentation that they did not regard as central to their work.

The issue for regulatory reform is the way in which this discretion is used. When Hutter's UK inspectors decided to negotiate improvements towards compliance, rather than reaching for the rule-book and sanctioning businesses, this was seen as a sensible compromise between the agency goals and the resources available. Businesses could escape penalties for quite a long period if they were sufficiently deferential in their promises about eventual compliance with the inspectors' standards. When the Saudi inspectors used discretion, they were vulnerable to allegations of corruption. The agency had adopted a Weberian model for judging their behaviour without recognizing its ideal-typical character. This limited the opportunities for internal discussion and the development of a shared and structured approach to the use of discretion beyond the subjective assessments of the individual inspector. At the same time, the agency could not function unless discretion was used. In the absence of an agreed culture of decision-making, inspectors had limited resources to resist the incursion of 
the traditional Saudi principles represented by wasta. These filled the gap left by a narrow rational-legal approach to organizational design. In effect, the Weberian model left more space for wasta to influence decisions because of its silence on possible alternatives that might better achieve the agency's goals.

\section{Conclusion}

This case study has allowed us to explore the phenomenon of bureaucratic corruption in a society that is representative of many in the Global South. Each society will, of course, have distinctive features. On the other hand, the uneasy co-existence of traditional and rationallegal principles of authority is common. Within such contexts, we have shown that 'corruption' is a complex phenomenon that will not easily be eradicated by simple legal or disciplinary means. While these may be relevant to grand corruption or legislative corruption, where the state is being looted for private gain, they seem to be less applicable to bureaucratic malpractices. There is an inevitable space for discretion at the street level. Discretion is necessary for workers to do their jobs. However, we do not have clear principles for distinguishing appropriate and inappropriate uses of this flexibility. Most of the existing literature has been based on inspectorates in developed countries, where discretion is generally considered to be acceptable because it rests on tacit but unexamined principles shared between researchers and researched. This study suggests that discretion may be labelled as corruption simply because those principles are not shared. The Saudi food inspectors are faced with a tension between being good Saudis, honouring the traditions represented by wasta, and being good rational-legal bureaucrats. The latter inevitably loses out, partly because it results in behaviour that is discreditable in the eyes of key audiences 
outside the agency and partly because the agency does not supply a compelling alternative that would justify disappointing those with a wasta claim on an inspector.

To the extent that bureaucratic corruption is a problem, it will only be solved by a better understanding of what constitutes it as a problem. In the enforcement contexts discussed in this paper, it is a negative judgement on something that is endemic to public agencies, the use of discretion. More progress might be made by debating the proper and improper uses of discretion by street-level workers than by insisting on a bright line between discretion and corruption. 


\section{REFERENCES}

Al-Awaji, I (1971) Bureaucracy and Society in Saudi Arabia, PhD Thesis. University of Virginia, Richmond VA.

Al-Awaji, I (1989) Bureaucracy and Development in Saudi Arabia: The Case of Local Administration. Journal of Asian and African Studies 24, 49-61.

Al-Mutairi, S (2013) Saudi Food Inspector: A Focused Ethnographic Study in Regulation and Law Enforcement. PhD Thesis, University of Nottingham.

Al-Mutairi, S, Connerton, I and Dingwall, R (2015) Food safety organisations in Saudi Arabia - Organisational, historical and future analysis. Food Control 47, 478-86.

Al-Saud, F (2000) Islamic Political Development: A Conceptual Analysis. Occasional Papers 18. United Association for Studies and Research, Annandale, VA.

Al-Yahya, KO (2009) Power-Influence in Decision Making, Competence Utilization, and Organizational Culture in Public Organizations: The Arab World in Comparative Perspective. Journal of Public Administration Research and Theory 19, 385-407.

Ang, YY (2016) Beyond Weber: Conceptualizing an Alternative Ideal Type of Bureaucracy in Developing Contexts. Regulation \& Governance 11, 282-98.

Barbalet, J (2018) Guanxi as Social Exchange: Emotions, Power and Corruption. Sociology $52,934-49$.

Bardhan, P (1997) Corruption and Development: A Review of Issues. Journal of Economic Literature 35, 1320-46.

Bittner, E (1967) The Police on Skid-Row: A Study of Peace Keeping. American Sociological Review 32, 699-715.

Champion, D (2003) The Paradoxical Kingdom: Saudi Arabia and the Momentum of Reform. C Hurst \& Co, London. 
Charmaz, K (2006) Constructing Grounded Theory: A Practical Guide through Qualitative Research. Sage Publications, London.

Cunningham, RB, Sarayrah, YK (1993) Wasta: The Hidden Force in Middle Eastern Society. Praeger, Westport, CT.

Davis, KC (1979) Discretionary Justice A Preliminary Inquiry. Louisiana State University Press, Baton Rouge, LA.

DiMaggio, PJ, Powell, WW (1983) The Iron Cage Revisited: Institutional Isomorphism and Collective Rationality in Organizational Fields. American Sociological Review 48, $147-60$.

Dingwall, R (1977) Atrocity stories and professional relationships. Sociology of Work and Occupations 4, 371-96.

Dingwall, R (1997) Accounts, Interviews and Observations. Pp. 51-65 in Miller, G. and Dingwall, R. (2002) Ethnomethodology and Law. Pp. 227-44 in Benazar, R. and Travers, M. (eds) Introduction to Law and Social Theory. Oxford, Hart Publishing.

Felson, M (2011) Corruption in the Broad Sweep of History. Pp. 12-17 in Graycar, A, Smith, RG (eds) Handbook of Global Research and Practice in Corruption. Edward Elgar, Cheltenham

Forsyth, M (2007) A Typology of Relationships between State and Non-State Justice Systems. The Journal of Legal Pluralism and Unofficial Law 39, 67-112.

General Authority for Statistics, Kingdom of Saudi Arabia (2018) Population by Gender, Age Groups and Nationality (Saudi/Non-Saudi). https://www.stats.gov.sa/en/5680 [Accessed July 10, 2018].

Gillespie, K, Okruhlik, G (1988) Cleaning up Corruption in the Middle East. Middle East Journal 42, 59-82.

Gillespie, K, Okruhlik, G (1991) The Political Dimensions of Corruption Cleanups: A Framework for Analysis. Comparative Politics 24, 77-95. 
Glaser, BG., Strauss, A (1967) The Discovery of Grounded Theory: Strategies for Qualitative Research. Aldine de Gruyter, New York.

Griffiths, J (1986) What is Legal Pluralism? The Journal of Legal Pluralism and Unofficial Law 18, 1-55.

Hawkins, K (1983) Environment and Enforcement. Regulation and the Social Definition of Pollution. Oxford University Press, Oxford.

Hawkins, K, ed. (1992) The Uses of Discretion. Oxford University Press, Oxford.

Heidenheimer, AJ (1970) Introduction. In: Heidenheimer, AJ (ed.) Political Corruption:

Readings in Comparative Analysis. pp. 2-28. Transaction Books, New Brunswick, NJ.

Hermer, J, Hunt, A (1996) Official Graffiti of the Everyday. Law and Society Review 30, $455-80$.

Hutchings, K, Weir, D (2006) Understanding Networking in China and the Arab World: Lessons for International Managers. Journal of European Industrial Training 30, $272-90$.

Hutter, B (1988) The Reasonable Arm of the Law? The Law Enforcement Procedures of Environmental Health Officers. Oxford University Press, Oxford.

Hyde, R (2015) Regulating Food-Borne Illness: Investigation, Control and Enforcement. Hart Publishing, Oxford.

Jain, AK (2002) Corruption: A Review. Journal of Economic Surveys 15, 71-121.

Kurer, O (2005) Corruption: An Alternative Approach to Its Definition and Measurement. Political Studies 53, 222-39.

Lipsky, M (1980) Street-Level Bureaucracy: The Dilemmas of the Individual in Public Service. Russell Sage Foundation, New York.

Merry, SE (1988) Legal Pluralism. Law and Society Review 22, 869-96. 
Morgan, B (2015) Upside Down and Inside Out: Regulators and Regulatory Processes in Contemporary Perspective. In Sarat, A and Ewick, P (eds) The Handbook of Law and Society pp. 150-67. Wiley, New York.

Municipality of Riyadh (2009) Reports of Public Department of Environmental Health. Riyadh.

NAZAHA (2012) Mission and Goals. National Anti-Corruption Commission, Riyadh. https://www.nazaha.gov.sa/en/About/Pages/Goals.aspx [Accessed 16 October, 2018]

NAZAHA (2015) Performance Summary Report of the National Anti-Corruption Commission 2011-2014. National Anti-Corruption Commission, Riyadh. https://www.nazaha.gov.sa/en/About/Documents/Performance\%20Summary\%20Rep ort $\% 200 f \% 20$ The $\% 20$ National\%20Anti-Corruption\%20Commission\%2020112014.pdf. [Accessed July 10, 2018].

New York Times (2017) Saudi Arabia Arrests 11 Princes, Including Billionaire Alwaleed bin Talal https:/www.nytimes.com/2017/11/04/world/middleeast/saudi-arabia-waleedbin-talal.html [Accessed 16 October, 2018]

Nolan García, KA, Aspinwall, M (2017) Restraining Gulliver: Institutional Reform and the Strengthening of State Capacity and Compliance. Regulation \& Governance https://doi.org/10.1111/rego.12181.

Piore, MJ (2011) Beyond Markets: Sociology, Street-Level Bureaucracy, and the Management of the Public Sector. Regulation \& Governance 5, 145-64.

Rice, G (2004) Doing Business in Saudi Arabia. Thunderbird International Business Review $46,59-84$.

'SAUDI ARABIA : Population Growth of the Whole Country' (2003) http://www.populstat.info/Asia/saudiarc.htm. [Accessed July 10, 2018]. 'Saudi Vision 2030' (2016) http://vision2030.gov.sa/en. [Accessed July 10, 2018]. 
Silbey, S (2011) The Sociological Citizen: Pragmatic and Relational Regulation in Law and Organizations. Regulation \& Governance 5, 1-13.

Snyder, F (1999) Governing Economic Globalization: Global Legal Pluralism and European Union Law. European Law Journal 5, 334-74.

Strauss, A, Corbin, J (1997) Grounded Theory in Practice. Sage, Thousand Oaks, CA.

Tlaiss, H, Kauser,S (2011) The Importance of Wasta in the Career Success of Middle Eastern Managers. Journal of European Industrial Training 35, 467-86.

Transparency International (2018) Corruption Perceptions Index 2017. https://www.transparency.org/news/feature/corruption_perceptions_index_2017 [Accessed July 10, 2018].

Travers, M, Manzo, JF (1997) Law in Action: Ethnomethodological and Conversation Analytic Approaches to Law. Dartmouth, Aldershot, UK.

Vaughan, D (1999) The Dark Side of Organizations: Mistake, Misconduct, and Disaster. Annual Review of Sociology 25, 271-305.

Weber, M (1964) The Theory of Social and Economic Organization. Free Press, New York. Wrong, M (2009) It's Our Turn to Eat: The Story of a Kenyan Whistleblower. Fourth Estate, London. 
Table 1 Saudi news reports about notoriety of Saudi inspectors

\begin{tabular}{lll}
\hline Newspaper & $\begin{array}{l}\text { Date \& } \\
\text { Issue }\end{array}$ & Event \\
& & \\
Okaz & 7 April & A bribe was offered to an inspector by a food business worker \\
& 2009 & in the northern region of Saudi Arabia for obtaining a health \\
& & card.
\end{tabular}

Al- $\quad 30$ August $\quad$ An inspector demanded a bribe from food business workers in

Eqtisadiah 2008 (5437) Riyadh for issuing a health card without medical examination .

A Riyadh 28 July The subject of a bribe that was refused by a food inspector 2009 from a food business worker in the southern region of Saudi (15009) Arabia.

Okaz 
27 August A bribe was offered to an inspector by a food business worker

2010 (3358) in the southern region of Saudi Arabia to overlook an unsafe food (beyond expiry date).

Nazaha $29 \quad$ An inspector demanded a bribe (SR 15,000) from citizen in

(News on December the western region of Saudi Arabia to overlook law an official $2014 \quad$ enforcement beyond municipal offences, and Nazaha arrested site) $\quad$ him. 
Figure 1 The process of data analysis using Grounded Theory 